\title{
RESEARCH
}

\section{The Influence of Weather on the Management of Acute ST Elevation Myocardial Infarction}

\author{
Helen Curran MD FRCPC', Stephen Fort MD FRCPC ${ }^{2}$, Osama Elkhateeb MD FRCPC ${ }^{2}$ \\ 'Interventional Cardiology Fellow, Division of Cardiology, Department of Medicine, Dalhousie University \\ ${ }^{2}$ Interventional Cardiologist, Division of Cardiology, Department of Medicine, Dalhousie University
}

\begin{abstract}
Objectives: To determine if seasonal and weather variables are associated with the onset of acute ST elevation myocardial infarction (STEMI).

Background: In acute myocardial infarction (AMI) the relationships between meteorological variables, seasonality, and mortality have been studied with diverging results. No studies have specifically evaluated the link between weather conditions, and the onset and subsequent invasive management of STEMI.
\end{abstract}

Methods: We analyzed data pertaining to all consecutive STEMI patients presenting to our center for primary percutaneous coronary intervention (PPCI) over a two-year period. Weather and climatic data were correlated to symptom onset, symptom-to-door, and door-to-balloon times for this cohort.

Results: Between April 1, 2008 and March 30, 2010, 254 patients with STEMI underwent PPCl at our center. The onset of STEMI had a circadian variation with most occurring during the second quarter of the day (6am - 12pm). Patients with symptom onset during this time had the shortest door-to-balloon times. More STEMIs occurred on mild snow days compared to heavy snow days $(p=0.02)$. There was no difference in door-to-balloon times for patients presenting on snow days versus no snow days. There was an increased risk of STEMI during extremes of temperature ( $<0$ degrees Celsius or > 20 degrees Celsius; $p=0.05$ ).

Conclusion: This study suggests both a circadian pattern and temperature influence on STEMI onset in this population. There was no significant relationship between other weather variables and STEMI onset or door-to-balloon times.

The concept of meteorological influences on the pathogenesis of AMI is intriguing. Numerous studies have evaluated the effects of weather variables, seasonal factors, and circadian patterns on the acute onset and outcome of myocardial infarction. There is a well-established circadian variation in the onset of AMI with the highest incidence occurring in the second quarter of the day (6am to $12 \mathrm{pm}) .^{1-3}$ Theories regarding the pathophysiology of such a relationship are diverse and include circadian fluctuations in hematological and sympathetic nervous system function. ${ }^{4,5}$ The seasonal patterns of AMI have been studied extensively in various geographical regions. There appears to be both an increased incidence of AMI and mortality from AMI in winter months. ${ }^{6-8}$ It has been speculated that colder temperatures are associated with increased mortality from AMI independent of season or geographic region. ${ }^{7-13}$ Barometric pressure, more specifically a rapid decrease in pressure, has been shown to correspond to an increased incidence of AMI. ${ }^{14}$ Other climatic variables such as precipitation, humidity, wind speed, and weather fronts have not shown consistent or convincing associations with the incidence of AMI. ${ }^{15,16}$

Weather and climate in Halifax is heavily influenced by Nova Scotia's location on the Atlantic Coast and is quite different from central and western Canada. The strong maritime influence prevents wide temperature fluctuations (usual range from -15 to $+25{ }^{\circ} \mathrm{C}$ ), and causes abundant precipitation year round in the form of snow, rain, fog and ice mixes. These climatic characteristics make Halifax an ideal location to study weather variables with respect to AMI.

Previous studies did not specifically consider the effects that weather may have on STEMI, a type of AMI that is caused by sudden and complete occlusion of a coronary artery by blood clot and that is identified by specific features on the electrocardiogram (ECG). The successful treatment of STEMI is dependant on prompt reperfusion of the occluded artery to prevent irreversible heart muscle death. In the recent 
past, thrombolytic drugs, which are used to dissolve clots, were the mainstay of treatment. More recently, evidence suggests that timely PPCI, involving opening the occluded coronary artery with balloons and stents, affords a more effective treatment option. STEMI guidelines are available that outline goals of care for these patients with a focus on providing efficient treatment. ${ }^{17-18}$ STEMI timelines beginning with the onset of heart attack symptoms to the time it takes to open the occluded artery in the hospital have been devised and are recorded by most centers to optimize patient management. For instance the time from symptom onset to first hospital presentation is measured as the "symptom onset-to-door time" and the time it takes from diagnosis of STEMI in the emergency department to inflating the first intracoronary balloon in the catheterization laboratory is called the "door-toballoon time."

There has been no investigation into the effect of weather on the presentation of patients with STEMI nor how this may influence the 'out of hours' response time of the catheterization lab. In this study we examined the relationship between season, circadian influence and weather variables on the acute onset and subsequent management times of STEMI managed with PPCI.

\section{Methods}

Setting

Halifax is the capital city of the province of Nova Scotia and the largest Atlantic Canadian city. The analysis took place at the Queen Elizabeth II Health Sciences Center (QEIIHSC) cardiac catheterization laboratory that offers a 24/7 PPCI program to a catchment area of over 400,000 people. The climate in Halifax is humid continental and homogeneous for the surrounding geographic population studied.

\section{Study Inclusion Characteristics}

This was a single center retrospective cohort study utilizing the Cardiovascular Health Information System (CVIS) database. This large database collects information about all patients admitted to hospital with myocardial infarction who proceed to percutaneous coronary intervention (PCI) in the cardiac catheterization laboratory at the QEIIHSC. The database was used to identify all consecutive STEMI patients, over the age of eighteen years, who were treated with PPCI at the QEIIHSC between April 1, 2008 and March 30, 2010. Procedure identification numbers established in the CVIS database were assigned to each patient in the cohort to maintain confidentiality and to facilitate analysis of data. Ethical approval for this study was granted by the Capital Health Research Ethics Board.

\section{Study Data Collection}

Weather data were collected from the Environment Canada National Climate Data and Information Archive. This publicly accessible online database contains detailed hourly, daily and monthly meteorological data for all Canadian provinces. For the purposes of this study seasons were classified as Winter (December-February), Spring (March-May), Summer (June-August) and Fall (September-November). Weather variables collected included: Hourly readings, daily summaries and monthly means for temperature, relative humidity, barometric pressure, precipitation (rainfall, snowfall, fog) and wind speed. Mild rainfall was defined as 0.001 to $5 \mathrm{~mm}$ and heavy as more than $5 \mathrm{~mm}$. Mild and heavy snowfalls were defined as $0.25-2.5 \mathrm{~cm}$ and more than $2.5 \mathrm{~cm}$, respectively. Symptom onset date and time, symptom-to-door and door-to-balloon times were used to correlate weather and seasonal variables with the acute STEMI cohort previously defined.

\section{Outcome Measure}

Incident ST elevation myocardial infarction as identified by symptoms and electrocardiographic features (ST elevation $>1 \mathrm{~mm}$ in two or more contiguous limb leads, $>2 \mathrm{~mm}$ in two or more contiguous precordial leads or new left bundle branch block) in patients necessitating PPCI.

\section{Statistical Analysis}

Circadian variation was analyzed by calculating the number of patients whose symptom onset began in each of four 6-hour periods of the day. Seasonal patterns and weather parameters were evaluated by comparing symptom onset time to month, season, and individual weather variables. We also examined the effect of these parameters on symptom onset-todoor times and door-to-balloon times for this cohort. Multivariate poisson analysis was used to determine the association between weather variables and STEMI onset. Quantitative data are reported as mean values \pm standard deviation and qualitative data are reported as percentages. Continuous variables are compared using t-testing and categorical variables are analyzed using Fisher's exact and $\chi^{2}$ tests. A p value less than 0.05 is considered statistically significant.

\section{Results}

During the study period, between April 1, 2008 and March 30, 2010, 254 patients with STEMI required PPCI at our center. The mean age was $60 \pm 12$ years 
and $75 \%$ were men (Table 1 ). The median symptomto-door and door-to-balloon times were 93 and 80 minutes, respectively. The onset of STEMI events had a circadian variation with most occurring during the second quarter of the day between $6 \mathrm{am}$ and $12 \mathrm{pm}$ $(\mathrm{p}=0.03)$ (Figure 1). Patients who had symptom onset during the second quarter of the day also achieved the shortest symptom-to-door and door-to-balloon times, whereas those experiencing symptom onset in the early hours of the morning (24:00-05:59 hrs) had the longest symptom-to-door time $(\mathrm{p}=0.003)$ and those during the evening (18:00-23:59 hrs) had the longest door-to-balloon time $(\mathrm{p}=0.004)$ (Table 2). There was
Table 1. Baseline characteristics and treatment times for the study cohort.

\begin{tabular}{ll}
\hline Baseline Characteristics & $\mathbf{n}=\mathbf{2 5 4}$ \\
\hline Age Mean (years; SD) & $60.4(12.2)$ \\
Male (\%) & $191(75.2 \%)$ \\
Door-to-Balloon Time Median (min; SD) & $80(52)$ \\
Symptom-to-Door Time Median (min) & 93 \\
Symptoms-to-Ballon Time Median (min) & 181 \\
\hline
\end{tabular}

$\mathrm{SD}=$ standard deviation

Table 2. The effect of Season, Climate, Symptom Onset, and Arrival Time on delayed Door-to-Balloon and Symptom-to-Door times.

\begin{tabular}{|c|c|c|c|c|c|c|}
\hline Condition & & $\mathbf{n}$ & $\begin{array}{l}\% \text { of patients } \\
\text { with Door-to- } \\
\text { Ballon time } \\
\text { median ( } 80 \mathrm{~min}) \\
\mathrm{n}=125\end{array}$ & p value & $\begin{array}{l}\% \text { of patients } \\
\text { with Symptom- } \\
\text { to-Door time } \\
\text { median ( } 93 \text { min) } \\
n=125\end{array}$ & p value \\
\hline \multirow[t]{4}{*}{ Temperature $\left({ }^{\circ} \mathrm{C}\right)$} & $<0$ & 88 & $47.7 \%$ & 0.9 & $47.7 \%$ & 0.9 \\
\hline & $0-10$ & 67 & $53.7 \%$ & & $47.8 \%$ & \\
\hline & $10-20$ & 90 & $47.8 \%$ & & $52.2 \%$ & \\
\hline & $>20$ & 9 & $44.4 \%$ & & $44.4 \%$ & \\
\hline \multirow[t]{5}{*}{ Weather Condition } & Clear & 84 & $54.8 \%$ & 0.6 & $46.4 \%$ & 0.3 \\
\hline & Cloudy & 84 & $42.9 \%$ & & $44.0 \%$ & \\
\hline & Fog & 24 & $45.8 \%$ & & $66.7 \%$ & \\
\hline & Rain & 35 & $54.3 \%$ & & $54.3 \%$ & \\
\hline & Snow & 27 & $48.1 \%$ & & $51.9 \%$ & \\
\hline \multirow[t]{4}{*}{ Season } & Winter & 72 & $48.6 \%$ & 0.8 & $45.8 \%$ & 0.6 \\
\hline & Spring & 56 & $46.4 \%$ & & $50.0 \%$ & \\
\hline & Summer & 55 & $54.5 \%$ & & $56.4 \%$ & \\
\hline & Fall & 71 & $47.9 \%$ & & $51.9 \%$ & \\
\hline \multirow[t]{4}{*}{ Symptom Onset Time } & $2400-0559 h$ & 56 & $50.0 \%$ & 0.004 & $69.6 \%$ & 0.003 \\
\hline & $0600-1159 h$ & 80 & $37.5 \%$ & & $42.5 \%$ & \\
\hline & $1200-1759 h$ & 63 & $46.0 \%$ & & $38.1 \%$ & \\
\hline & $1800-2359 h$ & 55 & $69.1 \%$ & & $50.9 \%$ & \\
\hline \multirow[t]{4}{*}{ Arrival Time } & $2400-0559 h$ & 37 & $56.8 \%$ & 0.07 & $59.5 \%$ & 0.4 \\
\hline & $0600-1159 h$ & 86 & $43.0 \%$ & & $51.2 \%$ & \\
\hline & $1200-1759 h$ & 69 & $42.0 \%$ & & $43.5 \%$ & \\
\hline & 1800h- $2359 \mathrm{~h}$ & 62 & $61.3 \%$ & & $46.8 \%$ & \\
\hline
\end{tabular}




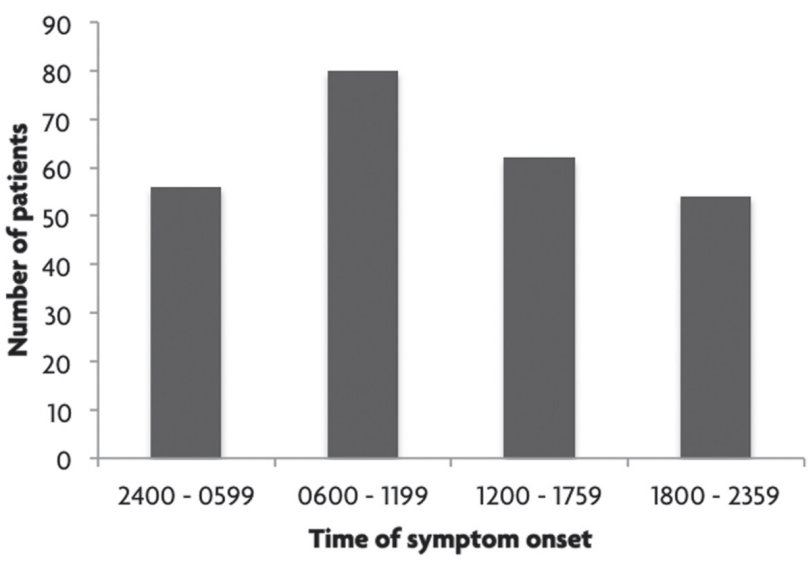

Figure 1. Circadian variation of symptoms.

no significant relationship between month or season and the incidence of STEMI (Figure 2).

The minimum and maximum temperatures during the study period were $-15{ }^{\circ} \mathrm{C}$ and $+32.1{ }^{\circ} \mathrm{C}$, respectively, with a mean of $11.8{ }^{\circ} \mathrm{C}$ (Table 3 ). The relative risk (RR) of having a STEMI was higher during the periods of temperature extremes defined as $<0{ }^{\circ} \mathrm{C}$ (RR 1.61, $\mathrm{p}=0.004)$ and $>20{ }^{\circ} \mathrm{C}(\mathrm{RR} 1.61, \mathrm{p}=0.01)$ (Table 4). However, neither symptom-to-balloon nor door-toballoon times were affected by temperature extremes.

The mean snowfall for the period of study was $0.63 \mathrm{~cm}$ with maximum of $30 \mathrm{~cm}$ (Table 3 ). Significantly more STEMIs occurred on mild snow days compared to no snow or heavy snow days ( $R R 1.61, \mathrm{p}=0.01$ ) (Table 4). However, snowfall or other types of precipitation including rain and fog did not influence symptom-todoor, or door-to-balloon times for STEMI (Table 2). There was no significant relationship between relative humidity or wind speed on the onset of STEMI in this cohort (Table 4).

\section{Discussion}

To our knowledge, this study is the first to evaluate the relationship between weather and the management of STEMI in a cohort of patients undergoing PPCI, and the first to evaluate the relationship between weather and AMI in Atlantic Canada.

Circadian influences on AMI are well documented and are reinforced in our study. ${ }^{1-3,5,8,12}$ Additionally, we found that patients who developed symptoms during the second quarter of the day (06:00-11:59 hrs) had significantly shorter symptom-to-door and door-toballoon times, than patients who developed symptoms during other times of the day. The latter finding is not entirely surprising as our catheterization laboratory operates between $8 \mathrm{am}-5 \mathrm{pm}$ and is not routinely staffed on evenings.
Table 3. Mean, minimum, and maximum values of weather variables for the study period.

\begin{tabular}{lllll}
\hline & Mean & SD & Min. & Max. \\
\hline Temperature $\left({ }^{\circ} \mathrm{C}\right)$ & 11.77 & 9.9 & -15.7 & 32.1 \\
Male $(\%)$ & 0.63 & 2.7 & 0 & 30 \\
Precipitation $(\mathrm{mm})$ & 3.5 & 8.8 & 0 & 83.2 \\
Wind speed $(\mathrm{km} / \mathrm{hr})$ & 35.3 & 24.3 & 0 & 104 \\
\hline SD = standard deviation & & & &
\end{tabular}

Our data suggest a significant relationship between temperature and the incidence of STEMI. STEMI was more common during temperature extremes, whereas other variables including season, rainfall, humidity and wind speed did not affect the relative risk of STEMI in this population. The deleterious effects of cold on the cardiovascular system have been extensively explored. The influence of cold air temperature on AMI is complex and multifactorial. ${ }^{9,12,21}$ Increased sympathetic tone and consequent elevations in blood pressure, heart rate and myocardial oxygen demand promote cardiovascular events. $^{3,25}$ Hematological and thrombogenic consequences of cold temperatures including increased blood viscosity, red cell count and fibrinogen levels may trigger AMI. ${ }^{20,22}$ Hot temperatures may have similar hematological and cardiovascular effects although the correlation is not as well defined. ${ }^{1921}$

Previous studies have described a U-shaped relationship between extremes of temperatures and mortality. ${ }^{21}$ A meta-analysis by Bhaskaran et al. (2009) described the adverse effects of both hot and cold temperatures on the short-term risk of myocardial infarction. ${ }^{22} \mathrm{~A}$ study assessing daily temperature and emergency room admissions for acute coronary syndromes found an increase in admissions when diurnal temperature

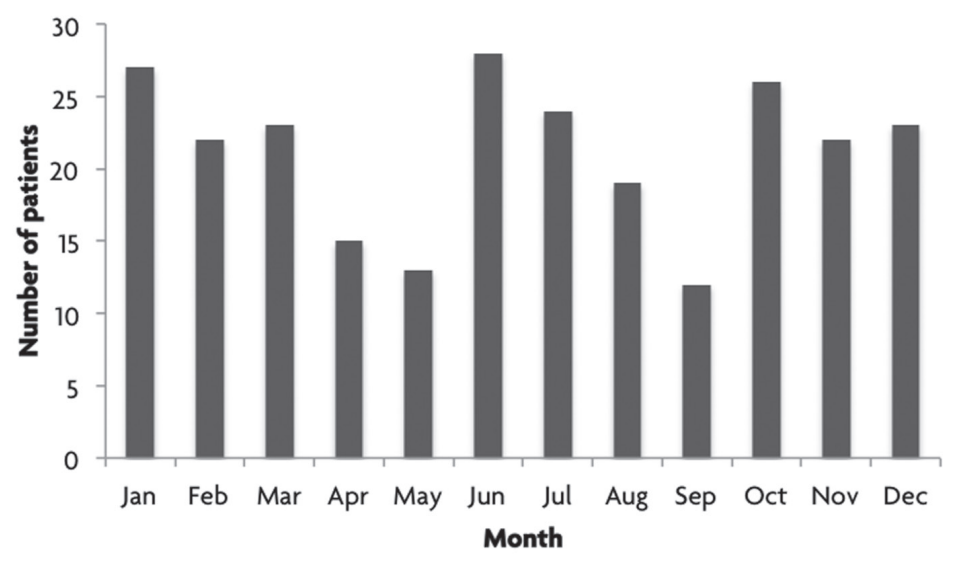

Figure 2. Symptoms by month. 
range was over 8 degrees. ${ }^{23}$ No studies have specifically evaluated the effect of temperature on acute plaque rupture and coronary thrombosis in STEMI.

We did not demonstrate a significant increase in STEMI during winter months. Similarly, there was no obvious relationship between season and symptom onset-to-door, or door-to-balloon times for this cohort. Our results differ from previous epidemiological and observational data that describe an increase in cardiovascular mortality in the winter, particularly in the elderly, and a peak in spring mortality for younger individuals, especially males. ${ }^{6,27,28}$ One explanation for our findings is that Halifax has comparatively modest temperature variation, and winters are warmer compared to inland regions. However, we did find an increased relative risk of STEMI during mild snow days compared to heavy snow days. This finding could in part relate to the phenomenon of the "snow shoveler's STEMI", in which the strenuous exertion associated with shoveling, particularly in the cold, can enhance plaque rupture and coronary thrombosis..$^{28,32,33}$ Snow shoveling may occur on days following a heavy snow fall (i.e. mild snow days) and as such could partly account for the increase in events on mild snow days..$^{28,32,33,35}$ Numerous studies have described increased cardiac events with strenuous exertion in the days following heavy snow fall. ${ }^{29-31}$ A rise in incidence of sudden cardiac death related to snow removal has been documented following snowstorms. ${ }^{31}$ More complex factors undoubtedly influence this finding. Fortunately, our data indicate that snowy days did not have longer symptomto-door or door-to-balloon times compared to days with no snow. It is reassuring that we are still able to achieve acceptable treatment times for these patients despite the influence of weather.

\section{Limitations}

There is inevitable internal correlation between the numerous weather variables that were studied. We used poisson regression analysis to find the combinations of variables that were most strongly associated with acute STEMI. Despite this, there may be inherent interactions between weather parameters making interpretation of associations difficult. We chose incident STEMI as an outcome measure but did not include mortality outcomes in this cohort. It should be noted that we studied a very select group of AMI patients because STEMI accounts for only a third of all AMI in Nova Scotia; many patients with STEMI outside of urban areas receive thrombolytics; and, many STEMI will die

Table 4. Multivariate Poisson analysis showing the Relative Risk of STEMI, according to weather and climatic variables.

\begin{tabular}{|c|c|c|c|c|c|}
\hline \multicolumn{2}{|l|}{ Condition } & $\begin{array}{l}\text { Days }^{*} \\
n=730\end{array}$ & $\begin{array}{l}\text { STEMI } \\
\mathrm{n}=\mathbf{2 5 4}\end{array}$ & $\mathbf{R}^{\dagger}$ & p value \\
\hline \multirow[t]{4}{*}{ Temperature $\left({ }^{\circ} \mathrm{C}\right)$} & $<0$ & 172 & 75 & 1.61 & 0.004 \\
\hline & $0-10$ & 258 & 70 & 1.24 & Reference \\
\hline & $10-20$ & 246 & 83 & 1.79 & 0.18 \\
\hline & $>20$ & 54 & 26 & 1.61 & 0.01 \\
\hline \multirow[t]{4}{*}{ Season } & Winter & 184 & 60 & 1.29 & 0.157 \\
\hline & Spring & 180 & 98 & 1.34 & 0.105 \\
\hline & Summer & 182 & 80 & 1.03 & 0.879 \\
\hline & Fall & 184 & 16 & 1.00 & Reference \\
\hline \multirow[t]{3}{*}{ Snow ${ }^{\ddagger}$} & No Snow & 627 & 209 & 1.00 & Reference \\
\hline & Mild Snow & 55 & 29 & 1.61 & 0.02 \\
\hline & Heavy Snow & 48 & 16 & 1.03 & 0.91 \\
\hline \multirow[t]{3}{*}{ Rain $\$$} & No Rain & 463 & 163 & 1.00 & Reference \\
\hline & Mild Rain & 140 & 50 & 1.02 & 0.90 \\
\hline & Heavy Rain & 127 & 41 & 0.93 & 0.66 \\
\hline \multirow[t]{3}{*}{ Wind Speed (km/hr) } & $<25$ & 191 & 68 & 1.03 & 0.82 \\
\hline & $26-55$ & 408 & 141 & 1.00 & Reference \\
\hline & $>61$ & 131 & 45 & 1.00 & 0.99 \\
\hline
\end{tabular}

STEMI: ST elevation myocardial infarction

"The number of days in which the variable occured.

$\dagger$ The relatives risks (RR) are derived from Poisson regression, adjusting for the number of days within each season or weather group.

\Snow categories are defined as: Mild $(0.25-2.5 \mathrm{~cm})$, Heavy $(>2.5 \mathrm{~cm})$

$\S$ Rain cateories are defined as: Mild $(0.001-5 \mathrm{~mm})$, Heavy $(>5 \mathrm{~mm})$ 
before reaching hospital. We chose to evaluate only the subset of patients with STEMI that were eligible for PPCI in order to identify the impact weather has on management times. Finally, this is a single center study involving a relatively small number of patients.

\section{Conclusions}

In this study we found a circadian pattern of STEMI onset in a population of Atlantic Canadian patients. An increased risk of STEMI was noted during extremes of temperatures, but there were no other significant associations between weather variables and STEMI onset or management times. Further research is needed to elucidate the true relationship between weather and the pathogenesis of acute ST elevation myocardial infarction. Weather does not seem to negatively influence the important benchmark management time goals of STEMI in this population.

\section{Acknowledgements:}

We acknowledge Dr. Ian Folkins, Associate Professor, Department of Physics and Atmospheric Science Dalhousie University, in addition to Tanya Shields, Data Quality Coordinator and the Interventional Cardiologists at the QEIIHSC in Halifax: Dr. Hussein Beydoun, Dr. Katherine Kells, Dr. Bakhtiar Kidwai, Dr. Michael Love, Dr. Najaf Nadeem, Dr. Ata Quraishi and Dr. Lawrence Title for their support and contribution to this research.

\section{References}

1. Muller JE, Stone PH, Turi ZG, Rutherford JD, Czeisler CA, Parker C, Poole K, Passaman E, Roberts R, Robertson T, Soebl B, Willerson J, Braunwald E and the MILIS Study Group. Circadian variation in the frequency of onset of acute myocardial infarction. New England Journal of Medicine 1985; 313: 1315-22.

2. Thompson DR, Sutton TW, Jowett NI, Pohl JG. Circadian variation in the frequency of onset of chest pain in acute myocardial infarction. British Heart Journal 1991; 65:177-8.

3. Marchant B, Ranjadayalan K, Stevenson R, Wilkinson P, Timmis A. Circadian and seasonal factors in the pathogenesis of acute myocardial infarction: the influence of environmental temperature. British Heart Journal 1993; 69: 385-87.

4. Muller JE, Tofler GH, Willich SN, Stone PH. Circadian variation of cardiovascular disease and sympathetic activity. Journal of Cardiovascular Pharmacology 1987; 10: 104-11.

5. Rocco MR, Nabel EG, Selwyn AP. Circadian rhythm and coronary artery disease. American Journal of Cardiology 1987; 59: 13C-7C.

6. Sheth T, Nair C, Muller J, Yusuf S. Increased winter mortality from acute myocardial infarction and stroke. Journal of the American College of Cardiology 1999; 33: 1916-19.

7. Ornato J, Peberdy M, Chandra N, Bush D. Seasonal patterns of acute myocardial infarction in the national registry of myocardial infarction. Journal of the American College of Cardiology 1996; 28: 1984-8

8. Gerber Y, Jacobsen S, Killian J, Weston S, Roger V. Seasonality and daily weather conditions in relation to myocardial infarction and sudden cardiac death in Olmsted County Minnesota 1979-2002. Journal of the American College of Cardiology 2006; 48:287-92.

9. Mannino J, Washburn R. Environment, temperature and mortality from acute myocardial infarction. International Journal of Biometeorology 1989; 33: 32-35.

10. Abrignani MG, Corrao S, Biondo GB, Renda N, Braschi A, Novo G, DiGirolama A, Braschi GB, Novo S. Influence of climatic variables on acute myocardial infarction hospital admissions. International Journal of Cardiology 2009; 137: 123-9.

11. Nayha S. Cold and the risk of cardiovascular disease. A review. International Journal of Circumpolar Health 2002; 61: 373-80.

12. McGeehin MA, Mirabelli M. The potential impacts of climate variability and change on temperature related morbidity and mortality in the united states. Environmental Health Perspectives 2001; 109: 185-9.

13. O'Neil MS, Ebi KL. Temperature extremes and health impacts of climate variability and change in the united states. Journal of Occupational and Environmental Medicine 2009; 51: 13-25.

14. Sarna S, Romo M, Siltanen P. Myocardial Infarction and Weather. Annals of Clinical Research. 1977; 4: 222-32.

15. Southern DA, Knudtson ML, Ghali WA, APPROACH Investigators. Myocardial infarction on snow days: incidence, procedure, use and outcomes. Canadian Journal of Cardiology 2006; 22: 59-61.

16. Goeme S, Eqli C, Gerber S, Defila C, Minder C, Richner H, Meier B. Impact of weather and climate on the incidence of acute myocardial infarction. International Journal of Cardiology 2007; 118: 36-40.

17. Montalescot G, Dallongeville J, Van Belle E, Rouanet S, Baulac C, Degrandsart A, Vicaut E for the OPERA Investigators. STEMI and NSTEMI: are they so different? One- year outcomes in acute myocardial infarction as defined by the ESC/ACC definition. The OPERA Registry. European Heart Journal 2007; 28: 1409-17.

18. Antman E, Hand M, Armstrong P, Bates E, Green LA, Halasyamani LK, Hochman J, Krumholz H, Mullany C, Sloan M. Focused Update of the ACC/AHA 2004 Guidelines for the management of patients with ST-elevation myocardial infarction: a report of the american college of Cardiology/American Heart Association Task Force on Practice Guidelines. Circulation 2008; 117: 296-329.

19. Hartz D, Golden J, Sister C, Chuang W, Brazel A. Climate and heat related emergencies in Chicago-Illinois (2003-2006). International Journal of Biometeorology 2010; 1: 92-3.

20. Goerre S, Egli C, Gerber S, Defla C, Minder C, Richner H, Meier $\mathrm{H}$. Impact of weather and climate on the incidence of acute coronary syndromes. International Journal of Cardiology 2007; 118: $36-40$

21. Keatinge WR, Donaldson GC, Cordioli E, Martinelli M, Kunst AE, Mackenbach JP, Nayha S, Vuori I. Heat related mortality in warm and cold regions of Europe: observational study. British Medical Journal 2000; 321:670-3.

22. Bhaskaran K, Hajat S, Haines A. Effects of ambient temperature on the incidence of myocardial infarction. Heart 2009; 95: 17601769.

23. Liang W, Liu W, Chou S, Kuo S. Ambient temperatures and emergency room admission for acute coronary syndromes in Taiwan. International Journal of Biometeorology 2008; 52: 223229.

24. Panagiotakos D, Chrysohoou C, Pitsavos C, Nastos P, Anadiotis A, Tentolouris C, Stefanadis C, Toutouzas P, Paliatsos A. Climatological variations in daily hospital admissions for acute coronary syndromes. International Journal of Cardiology 2004; 94: 229-233.

25. Hiramatsu K, Yamada T, Katakura M. Acute effects of cold on blood pressure, renin-angiotensin-aldosterone system, catecholamines and adrenal steroids in men. Clinical and Experimental Pharmacology and Physiology 1984; 11:171-9.

26. Douglas AS, Dunnigan MG, Allan TM, Rawles JM. Seasonal variation in coronary heart disease in Scotland. Journal of Epidemiology and Community Health 1995; 49: 575- 82.

27. Dunnigan MG, Harland WA, Fyfe T. Seasonal incidence and mortality of ischemic heart disease. Lancet 1970; 2:793-7 . 
28. Hammoudeh AJ, Haft JI. Coronary plaque rupture in acute coronary syndromes triggered by snow shoveling: editorial. New England Journal of Medicine 1996; 335: 2001-2002.

29. Ciampricotti R, Gamal MI, Bonnier JJ, Relik TH. Myocardial infarction and sudden death after sport: acute coronary angiographic findings. Catheterization and Cardiovascular Diagnosis 1989; 17:193-197.

30. Black A, Black MM, Gensini G. Exertion and acute coronary artery injury. Angiology 1975; 26: 759-783.

31. Chowdhury P, Franklin B, Boura J, Dragovic L, Kanluen S, Spitz W, Hodak J, O'Neill W. Sudden cardiac death after manual or automated snow removal. Journal of Cardiology 2003; 92:833835.

32. Janardhanan R, Henry Z, Hur D, Lin C, Lopez D, Reagan P, Rudnick S, Koshko T, Keelev E. The snow-shoveler's ST elevation myocardial infarction. American Journal of Cardiology 2010; 106: 596-600.

33. Franklin BA, Bonzheim K, Gordon S, Timmis GC. Snow shoveling: a trigger for acute myocardial infarction and sudden coronary death. American Journal of Cardiology 1996;77:855- 858.

34. Franklin BA, Hogan P, Bonzheim K, Bakalyar D, Terrien E, GordonS, Timmis GC. Cardiac demands of heavy snow shoveling. Journal of the American Medical Association 1995; 273: 880-882.

35. Franklin BA, George P, Henry R, Gordon S, Timmis GC, O’Neill WW. Acute myocardial infarction after manual or automated snow removal. American Journal of Cardiology 2001; 87:12821283

\section{cuadvertising}

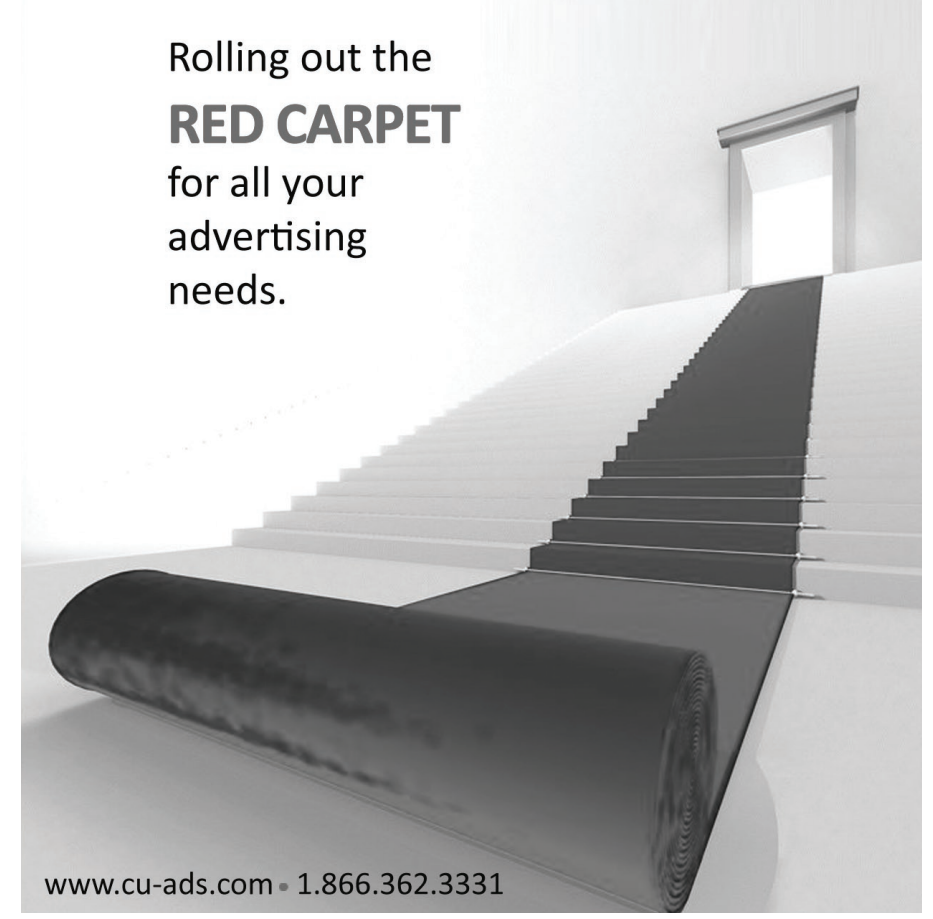

